\title{
Urgences
}

\section{Entre dehors et dedans}

\section{Marcel Boucher}

Numéro 10, 2e trimestre 1984

Spécial fantasmes

URI : https://id.erudit.org/iderudit/025155ar

DOI : https://doi.org/10.7202/025155ar

Aller au sommaire du numéro

Éditeur(s)

Urgences

ISSN

0226-9554 (imprimé)

1927-3924 (numérique)

Découvrir la revue

Citer ce document

Boucher, M. (1984). Entre dehors et dedans. Urgences, (10), 39-45.

https://doi.org/10.7202/025155ar

Ce document est protégé par la loi sur le droit d'auteur. L'utilisation des services d'Érudit (y compris la reproduction) est assujettie à sa politique d'utilisation que vous pouvez consulter en ligne.

https://apropos.erudit.org/fr/usagers/politique-dutilisation/
Cet article est diffusé et préservé par Érudit.

Érudit est un consortium interuniversitaire sans but lucratif composé de l’Université de Montréal, l'Université Laval et l'Université du Québec à Montréal. Il a pour mission la promotion et la valorisation de la recherche. https://www.erudit.org/fr/ 


\section{MARCEL BOUCHER}




\section{Entre dehors et dedans}

Je me parais bien loin

J'ois, couler la pluie

Je m'incarne entre dehors et dedans

Entre la mort et la vie

Entre hue et dia

Pas désagréable

Localité charmante, tranquille

Un peu morne, toutefois

Participer à rien

Mais entendre tout

Presque fantomatique

Je m'abandonne dans ce rêve

Je m'abandonne dans ce rêve, vous dis-je!

Sur la ligne de démarcation

Entre dehors et dedans. 


\section{Rosier en amour}

Mains chaudes à l'ivresse

Lèvres froides à la haine

Étreinte de reine

Cuisses de négresse

Vomissures du mauvais voyage Rêve picotté en points douleurs

Dans ses cheveux d'ange, je nage

Scaphandrier de ses douceurs

Mi-mauvaise, mi-belle

D'hallucinations

J'oublierai jamais, elle

Cette peau néon

Courant odieux

Pourtant si câlin

Pourtant adieux!

Matin si satin

La nuit nue

Tangue le lit de fer

Plancher qui pue

Aux hommes d'enfer

Rosier jambes ouvertes 
Simple marche

1-2-3-4 etc...

ou

3-4-7-8 etc...

ou

1-2-5-6 etc...

1- Bran de bûcheron

2- Misères neuves

3- Cicatrices maquillées

5- Bave de bois

6- Écorce ciselée

4- En zig zag

7- Épinette penchée

8- Peinée

9- Forêt ruche

11- Lac sort

10- Souffle d'élan

13- Truie fléchette

14- Bouche ouverte

17- Nénuphar vert

18- Son char vert

21- M'en

22- Allant

12- Ensorcelé

15- Lit d'os

16- Poils rubis

19- Yeux blancs

20- Paupières noires

23- Simplement

24- Pouf! 


\section{Printemps blanc}

Encaquer pour pleurer

Des sultanes en robes blanches

Apportent la potion magique

- Mangez monsieur! Les forces vont revenir

Un vieux, près de moi, ne mange plus

II ne croit plus aux magies

Avec des veines de plastique

Les sultanes lui sucent ses forces

Sans doute pour donner aux riches

Je me suis retrouvé là, un matin de printemps

Sans raison apparente

- Tu rêves trop, $t^{\prime}$ es pas normal

Que le sultan du Québec s'est écrié

En me voyant les yeux

Avec son araignée en plastique

II me grafigne le dos

Un vrai sorcier, maroufle

La petite fille sans rires

À l'opposé de mon lit

De force, mange son gruau matinal

Je la guette du coin des yeux

Jamais humain ne la visite

Elle mourra dans son lit blême

Tranquillement

Comme une rose frêle

Fin été gris

Elle

Fin printemps blanc. 


\section{Ombres à rebours}

Après avoir bu une tasse de froid

Dans le bois

Je retourne, les pieds dans la cuisine forêt

La maladie, hiver

$\mathrm{J}$ 'avais peur que tes larmes se transforment

De neige

Je me rappelle un délicieux bouquin

Ton coeur

Les nuages dehors aguichent le ciel

J'ouvre les pages

Un baiser d'ombres sur ma peau

Paroles lumières

Je hais la noirceur du chagrin

Vierge, nue-glace

Juste sur le sein des saisons

Dormons!

Robe de satin blanche, yeux de lune

II flotte tout près

Prendre le bateau diable 


\section{L'oubli qui chante.}

Ample piquant agouce son voisin

Le gentil tremble protège notre vieux garage

Clarté du jour

Brouille mes sentiments

Fermer, ternes rideaux

Journée qui s'éteint

Au fond, douce musique

Froidure solitaire qui chante

Comme un jardin de pierre

Ronger la main engourdie

Aussi la sentir caresser

Au paradis de I'oubli

Le rêve

Pleurer mon lac, mon pont, mon village

Que les gens engourdissent

Par ces paroles:

- Habille-toi autrement! 